\title{
Association of gene polymorphism methylenetetrahydrofolate reductase cytosine-to-thymidine substitution at nucleotide 677 with cardiovascular and metabolic risk in morbidly obese patients
}

\author{
(D) Rea Levicki*, \\ (D) Juraj Jug², \\ (DInes Vinković², \\ (DFilip Mustač², \\ (D)Martina Matovinović ${ }^{3}$, \\ (i)Lada Bradić ${ }^{3}$, \\ Jadranka Sertić ${ }^{3}$, \\ (D)Martina Lovrić \\ Benčićs
}

'Požega General County Hospital, Požega, Croatia 2University of Zagreb School of Medicine, Zagreb, Croatia ${ }^{3}$ University of Zagreb School of Medicine, University Hospital Centre Zagreb Zagreb, Croatia
RECEIVED:

August 5, 2019

ACCEPTED:

September 16, 2019

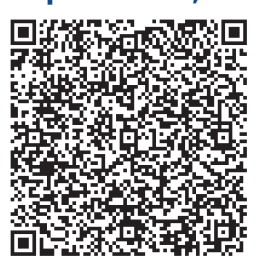

KEYWORDS: methylenetetrahydrofolate reductase, hypertension, diabetes.

CITATION: Cardiol Croat. 2019;14(9-10):235. | https://doi.org/10.15836/ccar2019.235

*ADDRESS FOR CORRESPONDENCE: Rea Levicki, Opća županijska bolnica Požega, A. Starčevića 4, HR-35000 Slavonski Brod, Croatia. / Phone: +385-98-550-309 / E-mail: rlevicki@gmail.com

ORCID: Rea Levicki, https://orcid.org/0000-0003-3687-1310 • Juraj Jug, https://orcid.org/0000-0002-3189-1518 Ines Vinković, https://orcid.org/0000-0003-1705-8295 • Filip Mustač, https://orcid.org/0000-0003-2851-6183 Martina Matovinović, https://orcid.org/0000-0002-6325-7394 • Lada Bradić, https://orcid.org/0000-0001-8296-699X Martina Lovrić Benčić, https://orcid.org/0000-0001-8446-6120

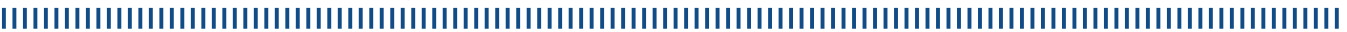

Introduction: Region near the gene encoding methylenetetrahydrofolate reductase (MTHFR) is among eight loci associated with blood pressure. ${ }^{1-3}$ The aim of this study is to show connection between polymorphism of MTHFR C667T and hypertension, diabetes, prediabetes and obstructive sleep apnea in obese Croatian patients.

Patients and Methods: We included 88 patients from a multidisciplinary weight management program in which genetic analysis on MTHFR gene polymorphism was tested. Patients were divided in 3 groups: 36 patients with MTHFR C677T healthy genotype CC (27 women, 9 men; age $46.4 \pm 10.1$ year; BMI $\left.44.9 \pm 8.8 \mathrm{~kg} / \mathrm{m}^{2}\right), 38$ patients with MTHFR C677T heterozygous mutation CT (27 women, 11 men; age $46.9 \pm 11.4$ year; BMI $\left.44.6 \pm 8.6 \mathrm{~kg} / \mathrm{m}^{2}\right), 14$ patients with MTHFR C677T homozygous mutation TT (12 women, 2 men; age 50.1 \pm 15.5 year; BMI $\left.40.2 \pm 6.9 \mathrm{~kg} / \mathrm{m}^{2}\right)$. In each group the incidence of hypertension, prediabetes, diabetes and obstructive sleep apnea (OSA) was determined.

Results: Patients with genetic mutation MTHFR C677T:CT (Figure 1) had the highest incidence of arterial hypertension (65.8\%), diabetes (18.4\%), prediabetes (18.4\%) and OSA (31.6\%) with the highest average apnea hypopnea index (AHI) of $17.3 \pm 24.7$, even $13.2 \%$ of patients used continuous positive airway pressure (CPAP). Patients with healthy genotype MTHFR C677T:CC had lower incidence of arterial hypertension (44.4\%), prediabetes (11.1\%), diabetes (13.9\%), OSA (25\%), average AHI $11.3 \pm 15.9$ and only $8 \%$ of patients used CPAP. Patients with MTHFR C677T:TT polymorphism had the lowest arterial hypertension incidence $(42.9 \%)$, the highest prediabetes incidence $(42.9 \%)$, middle OSA prevalence (28.6\%), AHI 7.7 \pm 7.6 .

Conclusion: MTHFR C677T:CT polymorphism is the most common gene polymorphism in our group of morbidly obese patients. MTHFR C677T:CT polymorphism compared to MTHFR

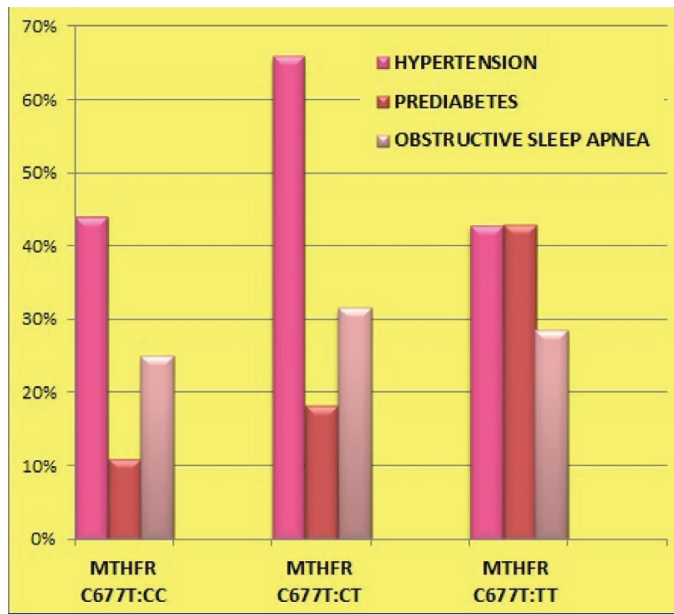

FIGURE 1. The graph shows hypertension, prediabetes and obstructive sleep apnea distribution in the group of patients with methylenetetrahydrofolate reductase cytosine-to-thymidine substitution at nucleotide 677 healthy genotype CC, heterozygous mutation CT and homozygous mutation TT.

MTHFR C677T:CC - methylenetetrahydrofolate reductase cytosine-to-thymidine substitution at nucleotide 677 healthy genotype CC; MTHFR C677T:CT - methylenetetrahydrofolate reductase cytosine-to-thymidine substitution at nucleotide 677 heterozygous mutation CT; MTHFR C677T:TT - methylenetetrahydrofolate reductase cytosine-to-thymidine substitution at nucleotide 677 homozygous mutation TT.

C677T:CC and MTHFR C677T:TT polymorphisms carries the highest risk for arterial hypertension, metabolic disorders (diabetes) and obstructive sleep apnea. Homozygotes MTHFR C677T:TT carries the highest risk for prediabetes. Further investigation is needed to explore this correlation.

\section{LITERATURE IIIIIIIIIIIIIIIIIIIIIIIIIIIIIIIIIIIIIIIIIIIIIIIIIIIIIIIIIIIIIIIIIIIIIIIIIIIIIIIIIIIIIIIIIIIIIIIIIIII} McNulty H, Strain JJ, Hughes CF, Ward M. Riboflavin, MTHFR genotype and blood pressure: A personalized approach to prevention and treatment of hypertension. Mol Aspects Med. 2017 Feb;53:2-9. https://doi.org/10.1016/j.mam.2016.10.002

2. Wu YL, Hu CY, Lu SS, Gong FF, Feng F, Qian ZZ, et al. Association between methylenetetrahydrofolate reductase (MTHFR) C677T/A1298C polymorphisms and essential hypertension: a systematic review and meta-analysis. Metabolism. 2014 Dec;63(12):1503-11. https://doi.org/10.1016/j.metabol.2014.10.001

3. Yigit S, Karakus N, Inanir A. Association of MTHFR gene C677T mutation with diabetic peripheral neuropathy and diabetic retinopathy. Mol Vis, 2013 Jul 25;19:1626-30. PubMed: https://www.ncbi.nlm.nih.gov/pubmed/23901246 